\title{
Value of Travel Time Savings in the Context of Leisure Travel in the Czech Republic
}

\author{
P. Šenk*, S. Biler, A. Daňková \\ Transport Research Centre, Brno, Czech Republic, \\ *Corresponding author: petr.senk@cdv.cz
}

DOI: $10.2478 / \mathrm{v} 10158-012-0024-1$

\begin{abstract}
This paper presents the results of a study focused on the estimation of the value of travel time savings in the context of long distance leisure travel by car. The study refers to the concept of willingness-to-pay for the reduction of travel time. Data on choice behavior were collected by means of a stated preference survey on a representative sample of the population in the Czech Republic and analyzed using methods of discrete choice analysis.

Results of the study suggest that, in case of the most common type of long distance leisure trips - weekend trips, estimated values of travel time savings obtained by the above mentioned methods are consistent with values recommended by literature, i.e. within the range of $25 \%$ and $50 \%$ of the average hourly wage. The study also confirms that the value of travel time increases together with trip length.
\end{abstract}

KEY WORDS: Value of travel time savings, conditional logit model, stated preference survey, willingness-to-pay.

\section{INTRODUCTION}

Value of travel time savings (VTTS) is one of the key inputs to transport planning models and tools for the management and appraisal of road investments decisions. Information on VTTS is essential for parameterization of destination, mode, route and departure time choice components of complex travel demand models. This paper describes the methodology and results of a study aimed at the valuation of travel time in the Czech Republic in the context of leisure travel by car.

Literature on the estimation of VTTS refers to two main approaches whose adequacy differs according to the purpose of travel (Bickel et al., 2006). The so-called cost saving approach is being used in the case of business trips, during which the travel time of employees is viewed as unproductive. For such types of trips the VTTS is equal to the monetary valuation of the employees' productive output. Cost saving approach is recommended also in the case of commercial goods traffic, where the main trip characteristics (for example, destination, route, and departure time) are given by the business policy of the employer. On the other hand, non-work trips, including commuting, shopping or leisure trips, are to a large extent determined by the driver himself. Is such cases it is appropriate to focus directly on the preferences of drivers and their willingness-to-pay for a reduction in travel time. 
Section 2 presents in details the method of willingness-to-pay that combines the stated preference method for data collection and the discrete choice modeling for data analysis. Section 3 provides a description of the data collection method and key descriptive statistics of the working dataset. Section 4 presents resulting values of travel time savings and section 5 a discussion of the results.

\section{METHODOLOGY}

\subsection{Discrete choice model}

In the study, the valuation of travel time savings refers to the basic economical concepts of utility theory and the theory of rational choice. According to these theories consumers (in our case drivers as the user of transport infrastructure) choose from a finite set of all available options that bring him or her the highest utility. Utility is understood as a linear combination of attributes assigned to each option (travel time, comfort, fuel consumption, etc.) and individual preference weights that individuals assign to each attribute.

Regarding the fact that neither analyst nor the consumer (driver) himself or herself is not able to reliably identify all attributes influencing the value of the perceived utility, the utility function is complemented with an error term that aggregates all factors unrecognized by the analyst. The general form of the utility function has the form

$$
U_{i}=V_{i}+\varepsilon_{i}
$$

where $U_{i}$ represents utility of option $i ; V_{i}$ represents factors influencing decision making that are known to the analyst; and $\varepsilon_{i}$ represents all remaining "unknown" factors.

The theory of rational choice suggests that the consumer (car driver) who faces alternatives $i$ and $j$ with utilities $U_{i}>U_{j}$ always chooses alternative $i$. However, if the utility function consists of the unknown component $\varepsilon_{i}$, as is also in our case, the result of choice becomes more difficult to predict. The presence of a random component in the utility function requires that the choice behavior has to be viewed as a stochastic process, in which the given consumer (driver) chooses the alternative $i$ with probability Prob $b_{i}$ that complies with the equation

$$
\operatorname{Prob}_{i}=\operatorname{Prob}\left(U_{i}>U_{j}\right)
$$

The decomposition of utility function to partial components leads to the equation

$$
\operatorname{Prob}_{i}=\operatorname{Prob}\left[\left(V_{i}+\varepsilon_{i}\right)>\left(V_{j}+\varepsilon_{j}\right)\right]
$$

this is due to the presence of random components called the rule of random utility maximization. Further adjustment leads to the equation

$$
\operatorname{Prob}_{i}=\operatorname{Prob}\left[\left(\varepsilon_{j}-\varepsilon_{i}\right)>\left(V_{i}-V_{j}\right)\right]
$$


which shows that the probability of choosing alternative $i$ is equal to the probability that the difference between unknown sources of the utility of alternatives $j$ and $i$ is higher than the difference between known sources of utility of alternatives $i$ and $j$.

Further, it may be shown that if random components $\varepsilon_{i}$ and $\varepsilon_{j}$ are drawn from type I extreme value distribution with probability function

$$
\operatorname{Prob}\left(\varepsilon_{j} \leq \varepsilon\right)=e^{-e^{-\varepsilon}}
$$

after certain arrangements made under certain conditions (for details see e.g. Maddala, 1983) it is possible to derive that the alternative $i$ is chosen over alternative $j$ with probability

$$
\operatorname{Prob}_{i}=\frac{e^{V_{i}}}{e^{V_{i}}+e^{V_{j}}}
$$

The equation above is a specific form of a discrete choice model for two alternatives - binary logit model.

\subsection{Implementation of a binary logit model in the willingness-to-pay method}

The method of willingness-to-pay consists of the estimation of a maximum sum of money people are willing to sacrifice in order to a gain certain merit, product or, conversely, eliminate negative consequences of their choice. In simple linear models, the willingness-topay may be derived as the proportion of parameter estimates related to one non-monetary attribute (in our case time) and one monetary attribute (in our case travel costs). Linearity of utility functions in discrete choice models thus enables the implementation of such kind of models in the willingness-to-pay method.

In our specific case, the value of travel time during trips to leisure activities is formulated as the maximum amount of money that are people are willing to sacrifice in order to save one unit of time, provided that all other trip related attributes remain constant. In our study we consider two hypothetical alternatives that differ in the following attributes:

- Fuel related costs $X_{\text {costs }}$ [in CZK];

- Travel time $X_{\text {time }}$ [in hours];

The utility function of alternatives $i$ and $j$ has the form:

$$
V_{i}=\beta_{\text {costs }} X_{\text {costs }}+\beta_{\text {time }} X_{\text {time }}
$$

resp.

$$
V_{j}=\beta_{\text {costs }} X_{\text {costs }}+\beta_{\text {time }} X_{\text {time }}
$$

where $\beta_{\text {costs }}$ and $\beta_{\text {time }}$ represent respective parameters that are going to be estimated from empirical data. 
Regarding the survey design (described in section 3), in which both alternatives are depicted only using the values of attributes and abstract names (e.g. route $\mathrm{G}$ ), the utility functions are free of alternative specific constants.

Parameters $\beta_{\text {costs }}$ and $\beta_{\text {time }}$ of the conditional logit model were estimated by the maximum-likelihood method using the survival package of statistical software $\mathrm{R}$ (R Development Core Team, 2008), namely the function $\operatorname{clogit}($ ). The final value of travel time savings VTTS was obtained by the substitution of the estimated values of $\beta_{\text {costs }}$ and $\beta_{\text {time }}$ to the formula

$$
\text { VTTS }=\frac{\beta_{\text {time }}}{\beta_{\text {costs }}} \cdot 60 \quad[\text { in } C Z K / h] .
$$

\section{DATA}

\subsection{Stated preference survey}

The aim of the stated preference survey is to estimate weights that consumers assign to particular attributes of available alternatives. Respondents of the survey are introduced to hypothetical scenarios, and provided with hypothetical choice alternatives that differ in the values of particular attributes and asked to choose one alternative based on their preferences.

The survey design consisted of the specification of a hypothetical situation with respect to the objective of the study, i.e. the estimation of the value of travel time in the case of leisure trips. In the study we focused on two basic scenarios: weekend leisure trips (two to three days) and holiday leisure trips (1 week and more). In the following text we will describe in detail the survey design.

In the stated preference experiment we assumed several hypothetical destinations (scenarios) that can be accessed by two alternative routes $i$ a $j$ that differ in the values of attributes $X_{\text {costs }}$ and $X_{\text {time }}$. In order to reduce alternative specific bias, routes were labeled by randomly generated letters (e.g. route D and route B). Further, a range of plausible values of attributes were calculated based on the assumption that a one way trip in the case of a weekend leisure travel resp. holiday travel takes about 1 hour 40 minutes, resp. 4 hours 30 minutes, which, in the case of an average speed of $70 \mathrm{~km} / \mathrm{hour}$, resp. $100 \mathrm{~km} / \mathrm{hour}$, corresponds to $117 \mathrm{~km}$, resp. $450 \mathrm{~km}$. The adequacy of the assumption was later confirmed by the results of the survey, in which respondents provided answers to the question "In the case of weekend leisure trip/holiday travel by car, what is the average distance traveled (return trip in $\mathrm{km}$ )?". The average distance provided by respondents was $126.5 \mathrm{~km}$, resp. $430.5 \mathrm{~km}$. Travel time values were set within $\mp 30$ minutes range around the average travel time, resp. within $\mp 60$ minutes range in the case of holiday travel; travel costs ranging from $270 \mathrm{CZK}$ for the shortest route and $390 \mathrm{CZK}$ for the longest route, resp. from $650 \mathrm{CZK}$ to $875 \mathrm{CZK}$.

With respect to the fact that variables $X_{\text {costs }}$ and $X_{\text {time }}$ are continuous, it was necessary to select a limited number of values so that we would be able to cover in sufficient detail the maximum range of travel time values, while keeping the number of decision problems as low as possible. The range of travel time values was set within the range of $10 \mathrm{CZK} / \mathrm{h}$ to $360 \mathrm{CZK} / \mathrm{h}$ in the case of weekend leisure travel and of $38 \mathrm{CZK}$ to $675 \mathrm{CZK}$ in the case of holiday travel, with respect to literature (Litman \& Doherty, 2009) that recommends values covering the range of $25 \%$ to $50 \%$ of average hourly wage $(143 \mathrm{CZK} / \mathrm{h}$ in second quarter 
of 2011) (MPSV, 2011). Finally fractional factorial design was used in order to generate a minimum number of value levels. For details on the procedure please refer to Hensher et al. (2005). Table 1 shows selected values of attributes.

Table 1: Attribute values in stated preference survey.

\begin{tabular}{|c|c|c|c|}
\hline \multicolumn{2}{|c|}{ Weekend leisure trips } & \multicolumn{2}{c|}{ Holiday travel } \\
\hline$X_{\text {time }}$ & $X_{\text {costs }}$ & $X_{\text {time }}$ & $X_{\text {costs }}$ \\
\hline $1 \mathrm{~h} 10 \mathrm{~min}$ & $270 \mathrm{CZK}$ & $3 \mathrm{~h} 30 \mathrm{~min}$ & $650 \mathrm{CZK}$ \\
\hline $1 \mathrm{~h} 35 \mathrm{~min}$ & $310 \mathrm{CZK}$ & $4 \mathrm{~h} 20 \mathrm{~min}$ & $725 \mathrm{CZK}$ \\
\hline $1 \mathrm{~h} 45 \mathrm{~min}$ & $350 \mathrm{CZK}$ & $4 \mathrm{~h} 40 \mathrm{~min}$ & $800 \mathrm{CZK}$ \\
\hline $2 \mathrm{~h} 10 \mathrm{~min}$ & $390 \mathrm{CZK}$ & $5 \mathrm{~h} 30 \mathrm{~min}$ & $875 \mathrm{CZK}$ \\
\hline
\end{tabular}

Each respondent of the survey was provided with 9 decision problems in each scenario that, according to fractional factorial design, systematically combined values in Table 1 and asked to choose his/her preferred route. Table 2 shows an example of the card with the decision problem.

Table 2: Example of card with decision problem used in the survey.

\begin{tabular}{|l|c|c|}
\hline Scenario 1 & Route G & Route D \\
\hline Costs related to fuel consumption & $70 \mathrm{CZK}$ & $130 \mathrm{CZK}$ \\
\hline Travel time & $1 \mathrm{~h} 45 \mathrm{~min}$ & $1 \mathrm{~h} 35 \mathrm{~min}$ \\
\hline
\end{tabular}

\subsection{Dataset}

The survey sample was selected from the population of residents in the Czech Republic using a stratified random sampling based on the register of addresses. 557 out of the total of 835 selected respondents agreed to participate in the survey, which corresponds to a $67 \%$ response rate. Sample representativeness was confirmed by the comparison of socio-demographical characteristics of the sample with characteristics of the population.

The survey was executed using the CAPI method. Each respondent was asked for his/her socio-demographic characteristics and basic characteristics of travel behavior in the context of leisure travel. Only respondents who indicated the use of car for a given type of leisure travel participated in the stated preference survey. The final dataset consists of 2502 choices from 278 respondents in the case of "weekend trip" scenario and 2061 choices from 229 respondents in the case of "holiday travel" scenario. 


\section{$4 \quad$ RESULTS}

Tables 3 and 4 show final values of parameters $\beta$ _costs and $\beta$ time estimated on the above described samples.

Table 3: Estimated parameters of conditional logit model in the case of "weekend trip" scenario.

\begin{tabular}{|c|c|c|c|c|}
\hline Attribute & Parameter estimate $\boldsymbol{\beta}$ & SE & z-score & $\operatorname{Pr}(>|\mathbf{z}|)$ \\
\hline$X_{\text {costs }}$ & $-0,041527$ & 0,002048 & $-20,27$ & $<0,001$ \\
\hline$X_{\text {time }}$ & $-0,038672$ & 0,002428 & $-15,93$ & $<0,001$ \\
\hline \multicolumn{4}{|l}{ R-square $=0,11$} \\
\hline
\end{tabular}

Table 4: Estimated parameters of conditional logit model in the case of "holiday travel" scenario.

\begin{tabular}{|c|c|c|c|c|}
\hline Attribute & Parameter estimate $\boldsymbol{\beta}$ & SE & z-score & $\operatorname{Pr}(>|\mathbf{z}|)$ \\
\hline$X_{\text {costs }}$ & $-0,012147$ & 0,000604 & $-20,11$ & $<0,001$ \\
\hline$X_{\text {time }}$ & $-0,023407$ & 0,001402 & $-16,69$ & $<0,001$ \\
\hline R-square $=0,13$ & & \\
\hline
\end{tabular}

Negative values of parameters correctly suggest that higher travel costs, respectively higher travel time, have a negative impact on utility. Low p-values suggest that estimated values of both parameters are different from zero at a fairly low significance level. Low values of Rsquare are associated with a high level of variability unexplained by the model. The analysis of relations between the value of travel time and socio-demographic characteristics of respondents was out of the scope of the study.

The value of travel time savings in the case of weekend leisure trips is

$$
\operatorname{VTTS}_{\text {weekend }}=\frac{\beta_{\text {time }}}{\beta_{\text {costs }}} \cdot 60=\frac{-0,038672}{-0,041527} \cdot 60=55,87[\mathrm{CZK} / \mathrm{h}] \text {, }
$$

and in the case of holiday travel

$$
V_{T T S_{\text {hlidays }}}=\frac{\beta_{\text {time }}}{\beta_{\text {costs }}} \cdot 60=\frac{-0,023407}{-0,012147} \cdot 60=115,62[\mathrm{CZK} / \mathrm{h}] .
$$

The estimated value of travel time savings in the context of weekend leisure trips is within the range referred in literature (Litman \& Doherty, 2009), i.e. 25\% - 50\% 
of the average hourly wage in the Czech Republic. A higher value of travel time in the context of holiday travel is in accordance with findings in other studies (Wardman, 1998). The reason may consist of the increase of marginal disutility of travel time with trip length due to fatigue, boredom and discomfort (Mackie et al., 2003).

\section{SUMMARY AND DISCUSSION}

This study presented an estimation of the value of travel time savings in the case of weekend leisure travel using the willingness-to-pay method that combined the stated preference survey and conditional logit model. It was shown that the estimated values of travel time savings are consistent with the values found in other countries.

However, it has to be noted that the study leaves several important issues unanswered, particularly due to the small sample size and limited scope of the study. Further study should focus on the influence of socio-demographic characteristics and detailed characteristics of the trip (e.g. trip length or other types of leisure travel) on the perceived value of travel time savings.

\section{ACKNOWLEDGEMENT}

The authors acknowledge financial support from the Foundation grant LD11059 of the Ministry of Education, Youth and Sports, Czech Republic.

\section{REFERENCES}

Bickel, P., Friedrich, R., Burgess, A., Fagiani, P., Hunt, A., Jong, G. D. \& Laird J. (eds.), 2006. Harmonised Guidelines for Project Assessment, Deliverable 5, HEATCO Developing Harmonised European Approaches for Transport Costing and Project Assessment, EC 6 FP. IER. Stuttgart: University of Stuttgart.

Hensher, D. A., Rose, J. M. \& Greene, W. H., 2005. Applied Choice Analysis: A Primer. Cambridge: Cambridge University Press. ISBN 0-521-60577-6.

Litman, T. A. \& Doherty, E., 2009. Transportation Cost and Benefit Analysis: Techniques, Estimates and Implications, 2nd edition. Victoria (British Columbia): Victoria Transport Policy Institute.

Mackie, P. J., Wadman, M., Fowkes, A. S., Whelan, G., Nellthorp, J. \& Bates, J., 2003. Values of Travel Time Savings UK. Working Paper 567 [online]. Leeds: Institute of Transport Studies, University of Leeds. 119 p. Retrieved from: http://eprints. whiterose.ac.uk/2079/.

Maddala, G. S., 1983. Limited- Dependent and Qualitative Variables in Econometrics. Cambridge: Cambridge University Press. 401 p. ISBN 0521338255.

MPSV, 2011. Informační systém o průměrném výdělku [online]. Praha: Ministerstvo práce a sociálních věcí. Retrieved from: http://www.mpsv.cz/files/clanky/11523/ISPV_112.pdf (in Czech) 
R Development Core Team, 2008. R: A Language and Environment for Statistical Computing [online]. ISBN 3-900051-07-0. Retrieved from: http://www.r-project.org/.

Wardman, M., 1998. The Value of Travel Time: A Review of British Evidence. Journal of Transport Economics and Policy, 32, pp. 285-316.

The article was produced under the support of the project

Transport R\&D Centre (CZ.1.05/2.1.00/03.0064) 